\title{
The Role of Rossby-Wave Propagation in a North American Extreme Cold Event
}

\author{
Chunhua Shi, ${ }^{1}$ Ting Xu, ${ }^{2}$ Hui Li, ${ }^{1}$ and Yannan Gao' \\ ${ }^{1}$ Key Laboratory of Meteorological Disaster, Ministry of Education (KLME)/Joint International Research Laboratory of \\ Climate and Environment Change (ILCEC)/Collaborative Innovation Center on Forecast and Evaluation of Meteorological Disasters, \\ Nanjing University of Information Science and Technology, Nanjing, China \\ ${ }^{2}$ Meteorological Bureau of Shenzhen Municipality, Shenzhen, China
}

Correspondence should be addressed to Chunhua Shi; shi@nuist.edu.cn

Received 22 May 2017; Accepted 12 July 2017; Published 17 August 2017

Academic Editor: Jia Yue

Copyright (C) 2017 Chunhua Shi et al. This is an open access article distributed under the Creative Commons Attribution License, which permits unrestricted use, distribution, and reproduction in any medium, provided the original work is properly cited.

\begin{abstract}
The Eliassen-Palm flux and Plumb wave activity flux are calculated using the European Centre for Medium-Range Weather Forecasts interim reanalysis daily dataset to determine the propagation of Rossby waves before a North American cold wave in January 2014. The results show that the upward wave activity fluxes mainly come from planetary waves 1 and 2, which provide a stable circulation background for the influence of the subplanetary-scale waves 3 and 4 . The Rossby-wave propagation anomalies between the troposphere and the stratosphere are due to the modulating effects of waves 3 and 4 on waves 1 and 2. During 9-14 January 2014, the modulating effects helped strengthen upward and eastward wave activity fluxes over the Atlantic region and enhance the Pacific high in the stratosphere in its early stage. Later in 19-24 January, the downward wave activity fluxes over the east Pacific due to the modulating effects were beneficial to downward development of the stratospheric high over the Pacific and the formation of a blocking high over the west coast of North America in the troposphere accompanied by a strong adjacent cold low on the east side. These circulations benefit the southward invasion of polar cold air reaching the lower latitudes of east North America, leading to the cold wave outbreak.
\end{abstract}

\section{Introduction}

The Arctic polar vortex is one of the most important atmospheric circulations in the Northern Hemisphere $(\mathrm{NH})$ winter and is also an important feature of the winter stratosphere. Cold wave outbreaks in the high latitudes of the $\mathrm{NH}$ winter are always associated with changes in the polar vortex [1-3]. It is easier for polar cold air to intrude farther south when the polar vortex is weak. Xiong et al. [4] suggested that Asian cold weather is mainly caused by polar vortex variation. During the extremely weak polar vortex of stratospheric sudden warming, the East Asian trough is strengthened and East Asia experiences cold events $[5,6]$.

To some extent, there are always interactions between the stratospheric polar vortex and wave activity of different scales [7]. Planetary wave activity can affect the intensity of the stratospheric polar vortex, and the anomalous stratospheric polar vortex can also have effects on the planetary waves (PWs). The interaction between the PWs and the stratospheric polar vortex anomaly can affect the short-term climate in the troposphere via a top-down mechanism [8]. When the polar vortex is weak, more stratospheric wave activities propagate polewards [9] and extreme cold events in the mid- and high latitudes occur more frequently [10].

Although most previous studies have suggested that variation of the polar vortex is mainly affected by PWs 1 and 2, some studies [e.g., [11]] have shown that the activities of transient waves are probably the main factor affecting the evolution of the stratospheric polar vortex. Transient waves are more active in the troposphere, but in some cases they can enter the lower stratosphere, where they interact with the PWs and have an implication to stratospheric anomalies [12]. Song and Robinson [13] pointed out that the response of the troposphere to the stratosphere is mainly caused by wave 3. Chshyolkova et al. [14] indicated that polar vortex disturbance in the stratosphere is the result of 


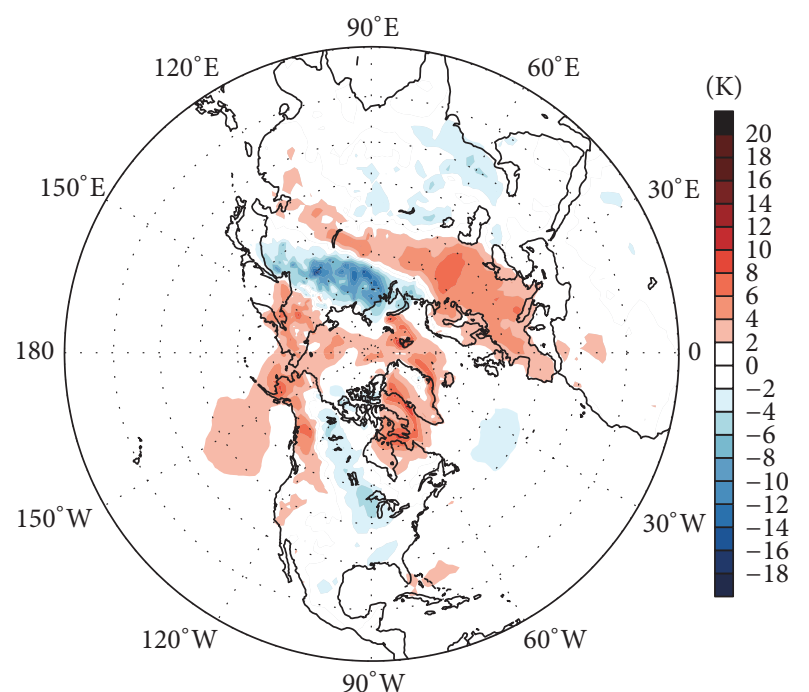

(a) 1-15 Jan anomaly

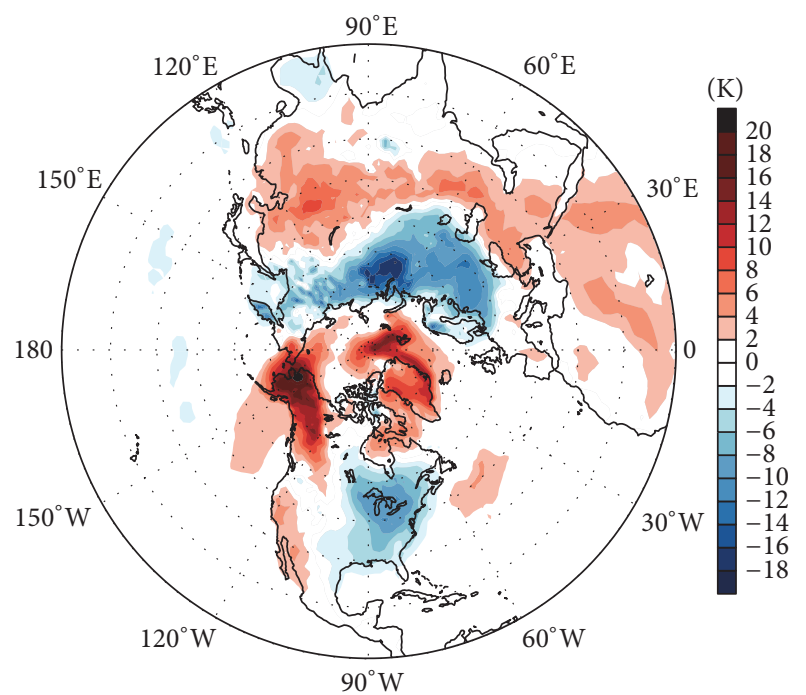

(b) 21-29 Jan anomaly

Figure 1: Composited 2-m surface temperature anomalies (shading; K) in January 2014 relative to the 30-year climatology: (a) composition for 1-15 January; (b) composition for 21-29 January. The 30-year climatology refers to the 30-year average of January in 1981-2010.

the interaction of PWs and transient waves. The blocking highs that usually accompany cold waves are more likely to resonate with subplanetary-scale waves. The effects of transient waves and PWs on atmospheric circulations are not separable, as these two types of waves modulate each other [15].

The polar vortex index [16-18], which is used for medium- and long-term weather forecasts, or the stratospheric northern annular mode index [19], which is used for short-term climate predictions [20], could be exploited to predict cold waves in weather forecasting, but attempts have not been very successful. One reason maybe of the underlying interaction between transient waves and planetary waves remains unclear. A North American cold wave in late January 2014 is used as an example in this paper. We focus on the modulating effects of the subplanetary-scale waves represented by waves 3 and 4 on the circulation evolution throughout the stratosphere-troposphere and explore the causes and precursor signals of extreme low-temperature events.

\section{Data and Methodology}

The European Centre for Medium-Range Weather Forecasts interim reanalysis global daily dataset is used in this study [21]. The Eliassen-Palm flux (EPF) [22] and the Plumb wave activity flux (WAF) [23] are calculated to determine the propagation of PW packets in two- or three-dimensional space, as mentioned by Shi et al. [24].

\section{Circulation Characteristics during the Cold Wave}

The 2-m surface temperature anomaly shows two different patterns in January 2014 (Figure 1). In the first half of January (Figure 1(a)), the temperature anomaly in the $\mathrm{NH}$ is relatively weak and is mainly located north of $50^{\circ} \mathrm{N}$ latitude, with the cold anomaly located in Siberia. In late January (Figure 1(b)), the temperature anomaly is stronger. In the high latitudes north of $50^{\circ} \mathrm{N}$, the cold anomaly is mainly located in the eastern hemisphere and the warm anomaly in the western hemisphere. In the mid-latitudes south of $50^{\circ} \mathrm{N}$, a new temperature anomaly center appears, with a cold center of $-10 \mathrm{~K}$ located in east North America, while Eurasia has a warm anomaly. In winter, the effects of cold waves at the same intensity are much stronger in the mid-latitudes than in the high latitudes. Therefore, it is worth studying this continuous extreme cold event in east North America in late January 2014.

Based on the daily variation of the 500-hPa geopotential height and its departure from the climatology (Figure 2), the formation of the Alaskan blocking high and deepening of the North American trough (Figure 2(d)) are the most important factors contributing to the continuous intrusion of cold air into east North America. During 9-14 January (Figures 2(a) and 2(b)), the Alaskan ridge develops, the North American trough deepens, and the Atlantic ridge moves westwards and is strengthened. On 19 January (Figure 2(c)), both the Alaskan and Atlantic ridges are weakened, the North American trough moves eastwards, and the polar low in the trough extends to the lower latitudes. On 24 January (Figure 2(d)), the Alaskan high ridge and the Atlantic high ridge anomalously strengthen to form two blocking highs, which divide the polar vortex over east North America, corresponding to the extreme cold in east North America around 24 January. On 29 January (Figure 2(e)), the westward Atlantic high ridge retreats to the east coast of North America, and the polar vortex shrinks and remains in east North America, maintaining the extreme cold.

The evolution of the polar vortex and the anticyclone in the middle stratosphere (Figure 3) indicate that the stratospheric circulation is related to the tropospheric circulation. 


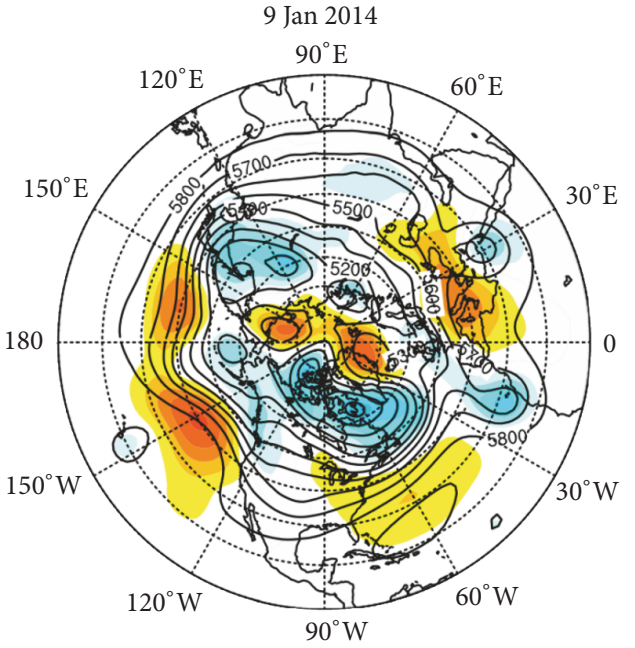

(a) $500 \mathrm{hPa}$

19 Jan 2014

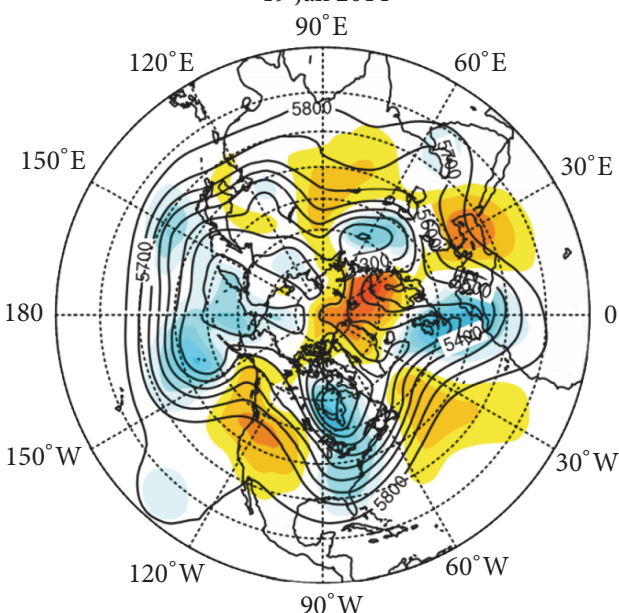

(c) $500 \mathrm{hPa}$

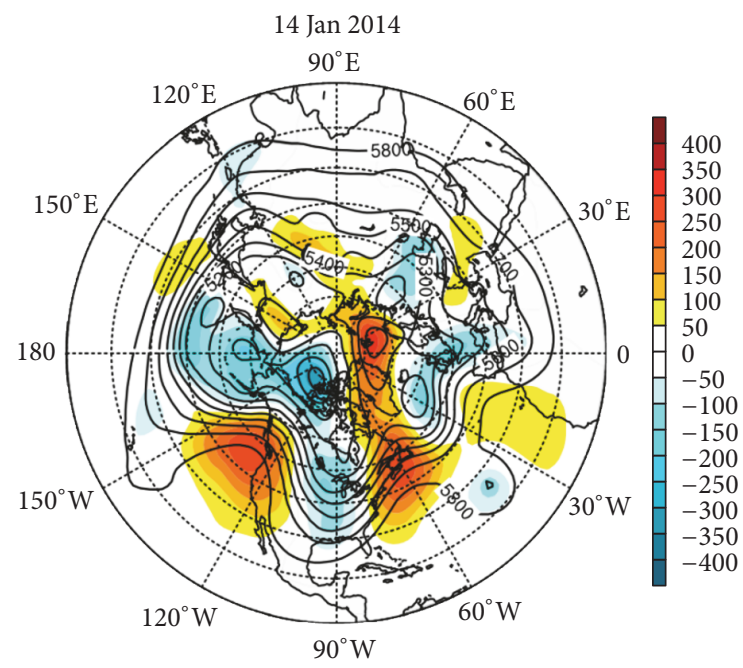

(b) $500 \mathrm{hPa}$

24 Jan 2014

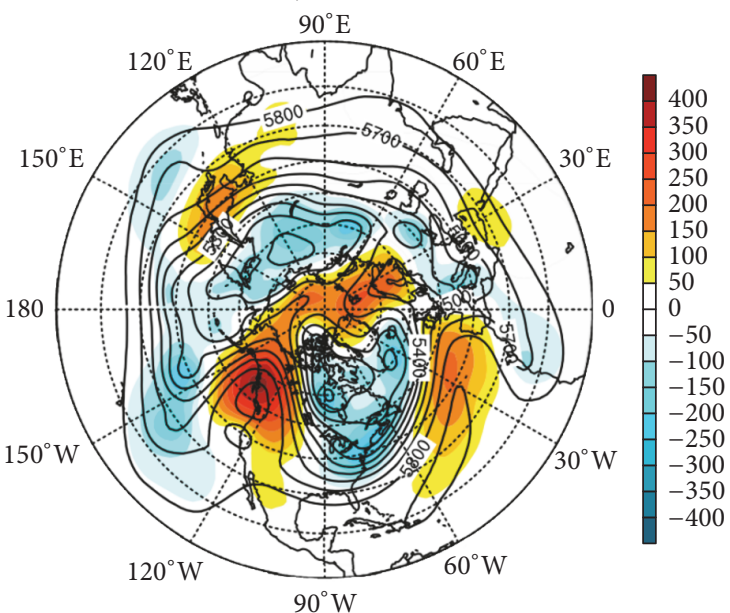

(d) $500 \mathrm{hPa}$

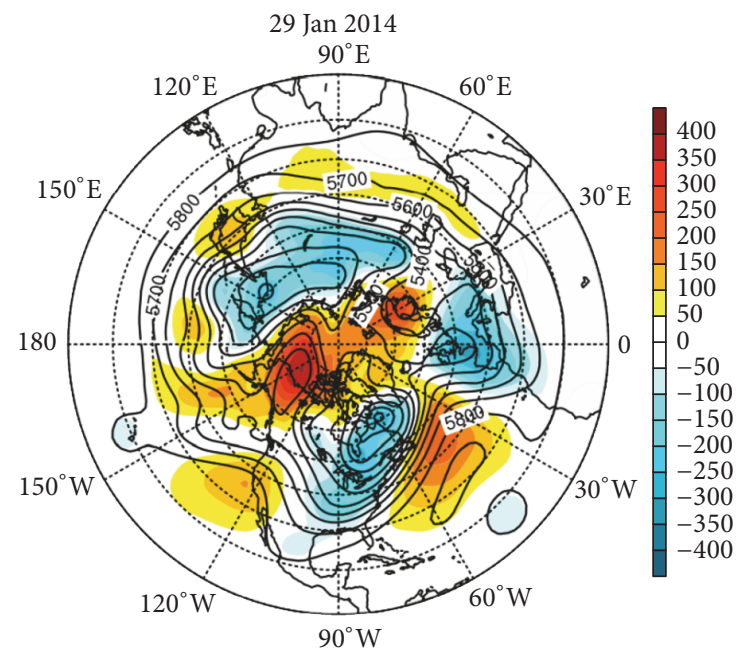

(e) $500 \mathrm{hPa}$

FIGURE 2: Daily geopotential height (contours; gpm) and its anomalies (shading; gpm) at 500 hPa in January 2014 relative to the 30 -year climatology. The 30-year climatology refers to the 30-year average of January in 1981-2010. Contour interval: 100 gpm. 


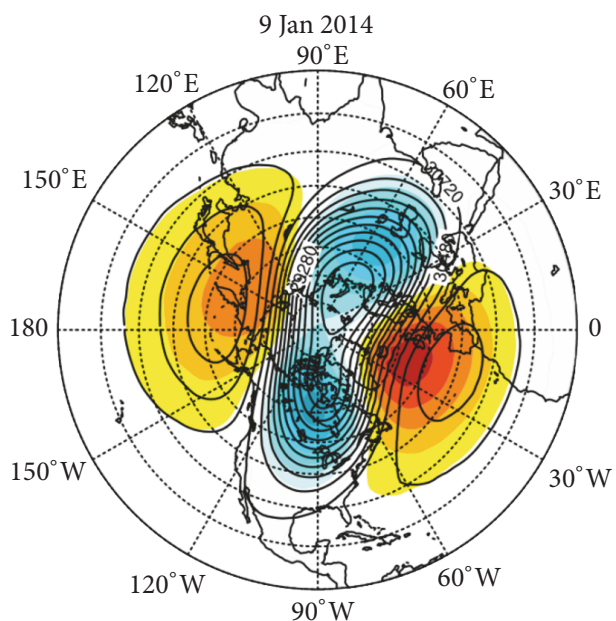

(a) $10 \mathrm{hPa}$

19 Jan 2014

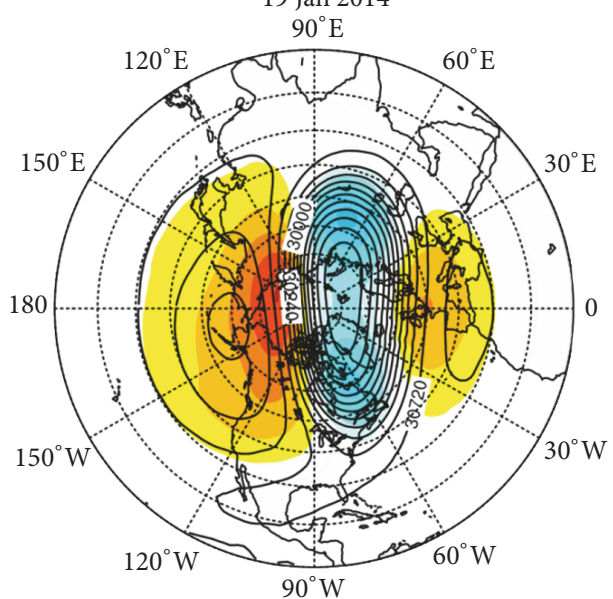

(c) $10 \mathrm{hPa}$
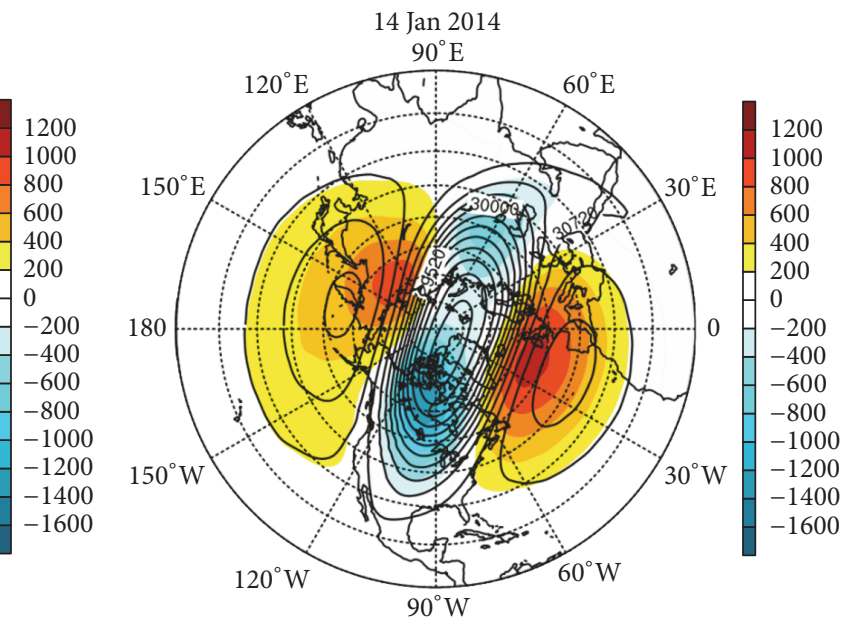

(b) $10 \mathrm{hPa}$

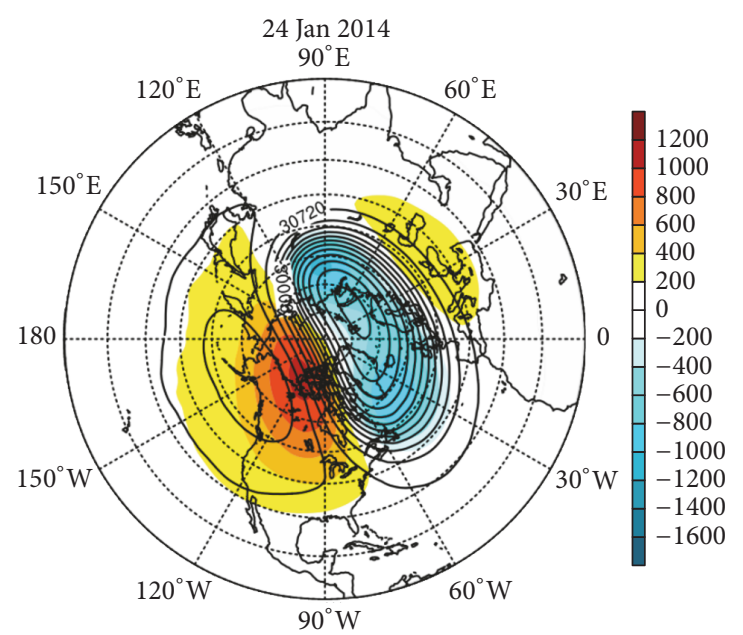

(d) $10 \mathrm{hPa}$

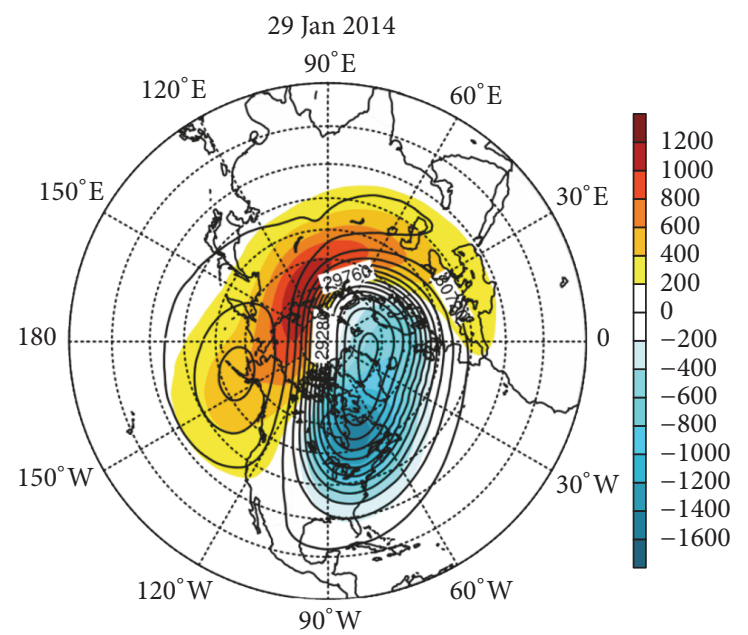

(e) $10 \mathrm{hPa}$

Figure 3: Daily geopotential height (contours; gpm) and its anomaly (shading; gpm) at $10 \mathrm{hPa}$ in January 2014 relative to the 30 -year climatology. The 30-year climatology refers to the 30-year average of January in 1981-2010. Contour interval: 240 gpm. 


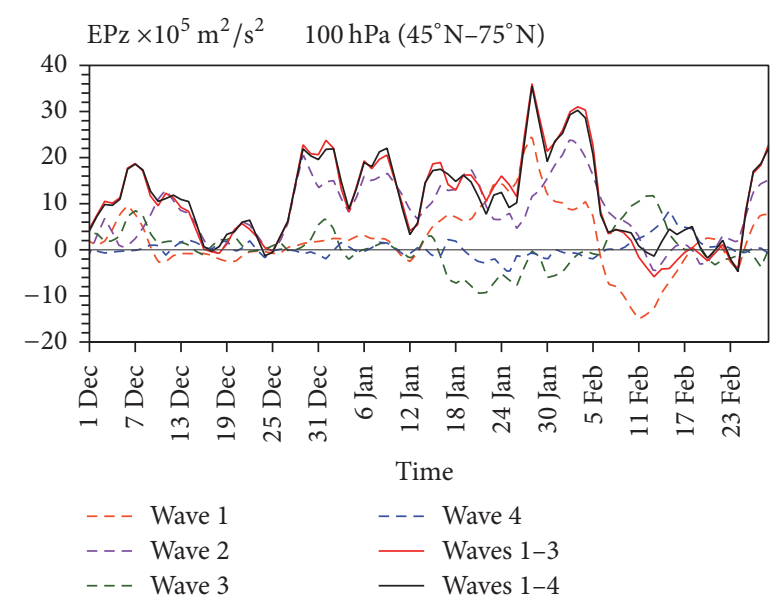

FIGURE 4: Time series of the vertical component of the EPF for waves $1-4$ (curves; $10^{5} \mathrm{~m}^{2} \mathrm{~s}^{-2}$ ) over $45^{\circ}-75^{\circ} \mathrm{N}$ at $100 \mathrm{hPa}$ from December 2013 to February 2014.

During 9-14 January (Figures 3(a) and 3(b)), the polar vortex splitting is responsible for the PW 2 pattern, and the Atlantic high is stronger than the Pacific high at $10 \mathrm{hPa}$. From 19 January (Figure 3(c)), the polar vortex shrinks, the Atlantic high gradually weakens, and the Pacific high increases. On 24 January (Figure 3(d)), the stratospheric circulation converts to a vortex displacement pattern (i.e., PW 1 pattern). On 29 January (Figure 3(e)), the Pacific high enhances and moves eastwards, and the polar vortex significantly extends to east North America and invades the lower latitude region of $30^{\circ} \mathrm{N}$.

The evolution of the stratospheric polar vortex and its adjacent high (Figure 2) and the variation of tropospheric circulation (Figure 3 ) are cooperative, especially in the early stage of the positive anomaly of the stratospheric Atlantic ridge and then in the enhancement of the stratospheric Pacific high and the formation of tropospheric Alaskan blocking high. The relationship between the above systems and its impact on the North American cold wave are discussed in Section 4.

\section{Rossby-Wave Propagation and Circulation Anomaly}

Usually, stratospheric polar vortex disturbance and Rossbywave activity are related. In January 2014, the intensity and trend of the vertical WAF for waves 1-3 and waves 1-4 are roughly the same as the evolution of PW 2 (Figure 4). In early January, the WAFs of wave 1 , wave 3 , and wave 4 remain near the zero line. After 12 January, the upward WAF of PW 1 is increased, while the downward flux of wave 3 is increased. Around 22 January, the downward WAF of wave 3 is at its strongest, the upward flux of PW 2 is weakened, the upward flux of PW 1 is more than PW 2, and the total WAFs for waves 1-3 reach a minimum. After the cold wave outbreak on 24 January, the increase in PW 2 activity takes the total flux up to a maximum value. The pattern of wave activity for
PWs 1 and 2 is consistent with the circulation mode shown in Figure 3.

In general, the stratospheric circulation anomalies are related to the activity of PWs 1 and 2 (Figure 3), but the subplanetary-scale waves represented by wave 3 (in Figure 4) have an important influence on the vertical propagation of wave activity. Therefore, the relationship between the wave activity anomaly and the transformation of the circulation structure is worth studying. For instance, how do the stratospheric high anomalies transfer from the Atlantic to the Pacific (in Figure 3)? How is the North American blocking high established (in Figure 2(d))?

The three-dimensional WAF describes the local characteristics of wave propagation. Figures 5 and 6 show the longitude-pressure cross-sections of the daily $50^{\circ}-70^{\circ} \mathrm{N}$ WAF and its vertical component (WAFz) for different wave numbers. For the composited WAF of PWs 1 and 2 (Figures 5(a1)-5(a5)), upward wave activities are mainly located in the Pacific and the continents on both sides, which helps maintain the Pacific high in the stratosphere. Although the wave activities of waves 1-3 (Figures 6(a1)-6(a5)) and 1-4 (Figures 6(b1)-6(b5)) are similar, the significant difference in WAF between waves 1-4 and waves 1 and 2 (Figures 5(a1)-5(a5)) suggests that waves 3 and 4 have important modulating effects on PWs 1 and 2.

The modulating effects of waves 3 and 4 help strengthen the upward WAFs over the Atlantic region and enhance the stratospheric Pacific high in its early stage (Figures 6(bl) and 6(b2)). Later in 19-24 January, the downward WAFs over the east Pacific, due to the modulating effects, are beneficial for downward development of the stratospheric high over the Pacific and the formation of a blocking high over the west coast of North America in the troposphere (Figures 6(b3), 6(b4), and 2). Based on the temperature and geopotential height anomalies (Figures 5(b1)-5(b5)), the stratospheric Atlantic high, which is in its strongest stage (Figure 3(a)), has a deep vertical structure on 9 January. In the same period, the upward WAFs originate from the lower part of the high (red shading and vectors in Figures 6(a1) and 6(b1)). On 14 January, the Atlantic high is weakened, and the upward and eastward WAFs located in East Asia strengthen the Pacific high in the middle stratosphere (Figures 6(a2) and 6(b2)). On 19 January, the Atlantic high is further weakened, the stratospheric Pacific high is at its strongest, a large downward WAF occurs on the east side of the Pacific high, and both the high and adjacent low on the east side develop downward (Figures 6(a3) and 6(b3)). On 24 January, due to the downward WAF, the high near the surface reaches its maximum strength (Figure 6(b4)), the blocking is maturing on the west coast of North America, and the adjacent surface low in east North America is also strong (Figure 2(d)). The northerly winds between the blocking and the low are beneficial for guiding the southward intrusion of Arctic cold air, corresponding to the outbreak of a cold wave in east North America. On 29 January, the downward WAF anomaly tends 


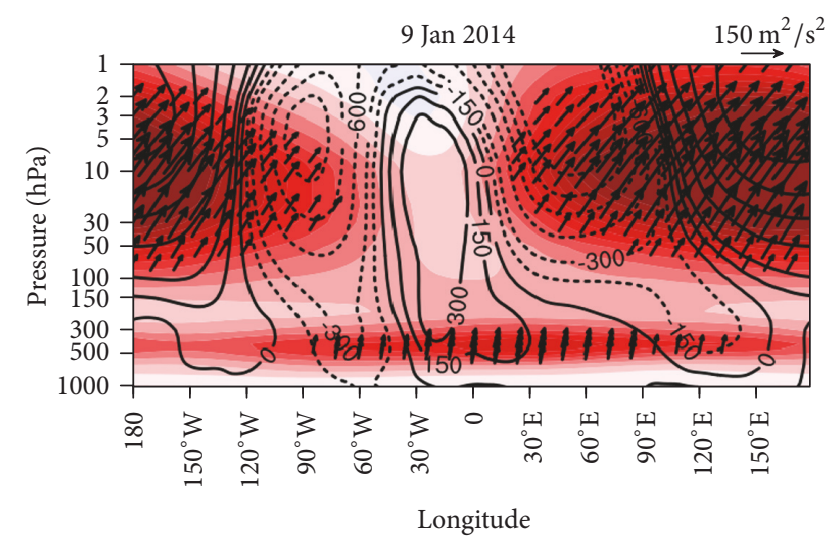

(a1) Waves 1-2

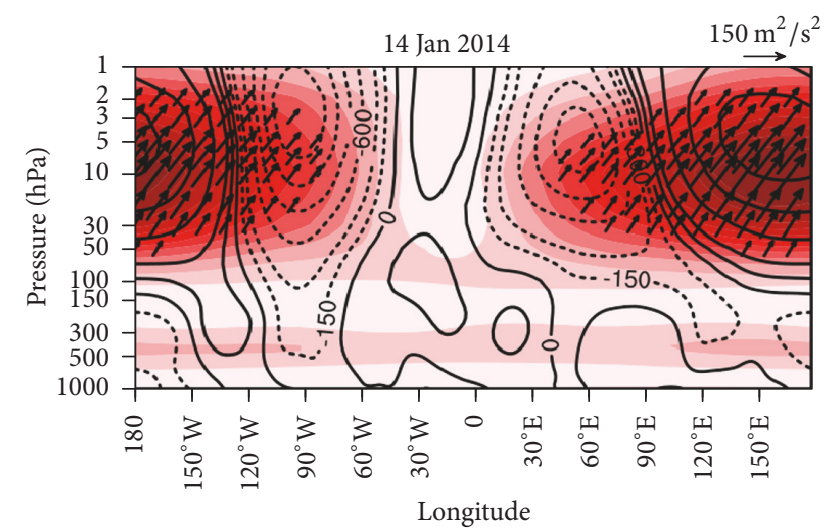

(a2) Waves 1-2

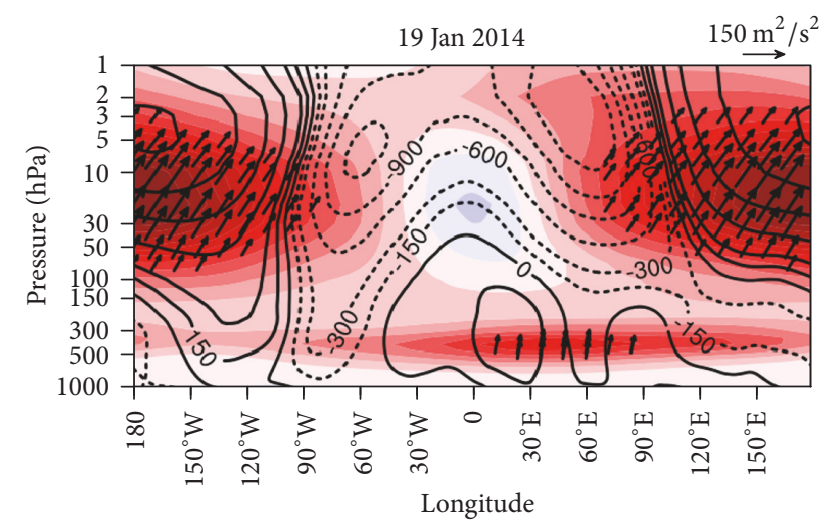

(a3) Waves 1-2

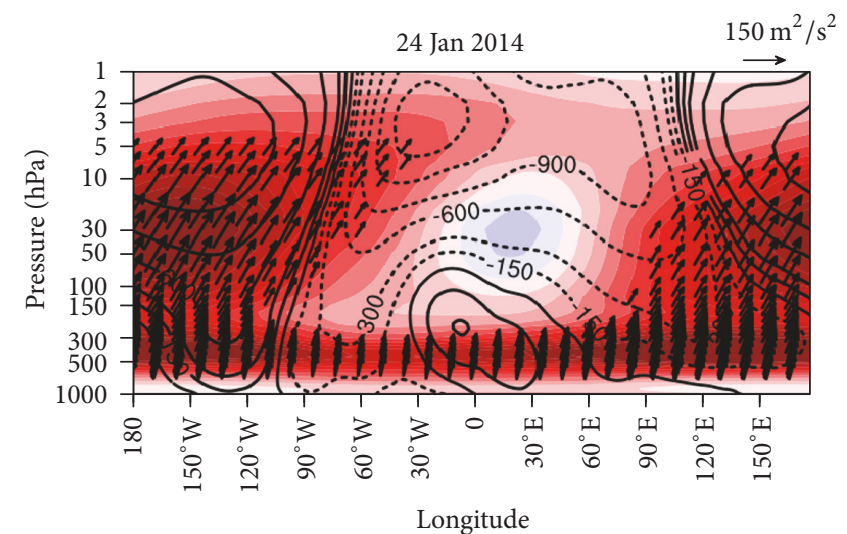

(a4) Waves 1-2

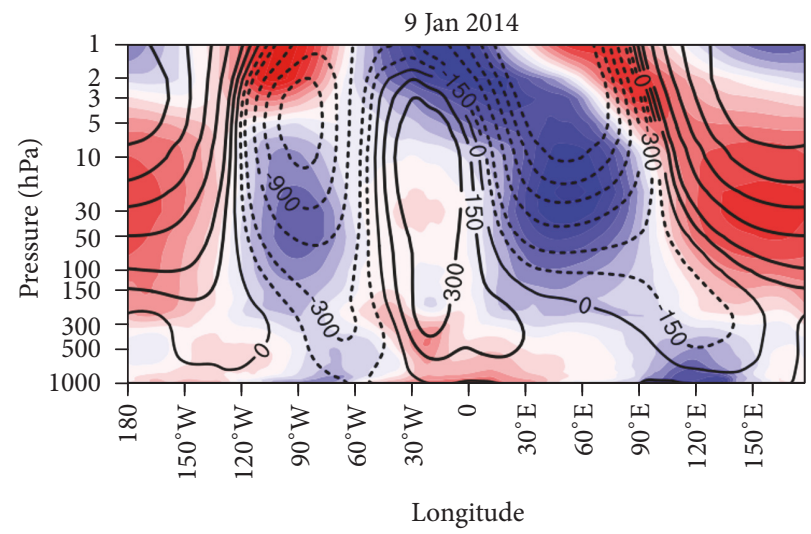

(b1)

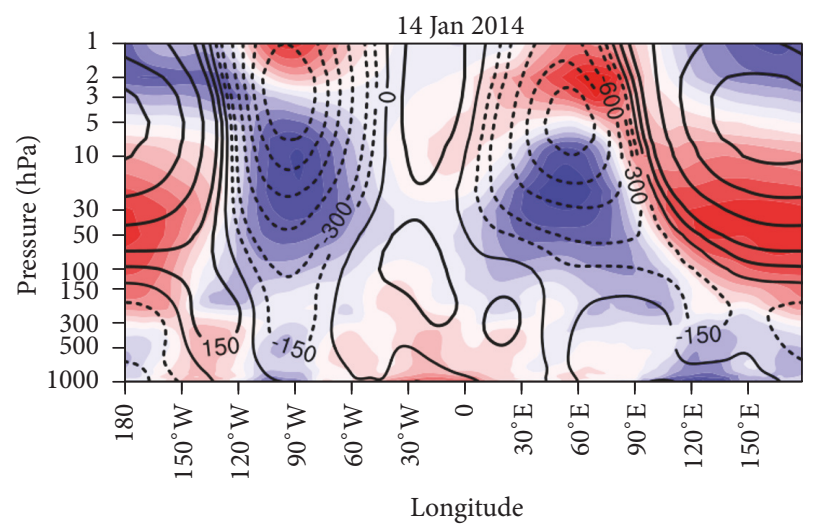

(b2)

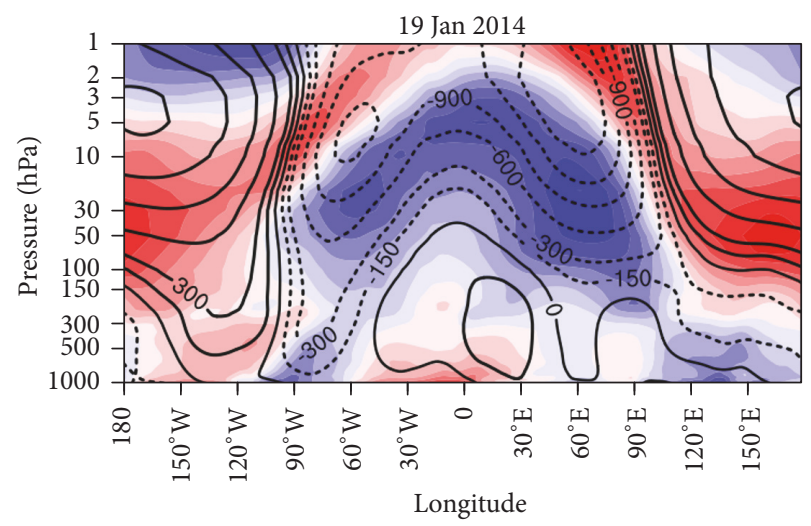

(b3)

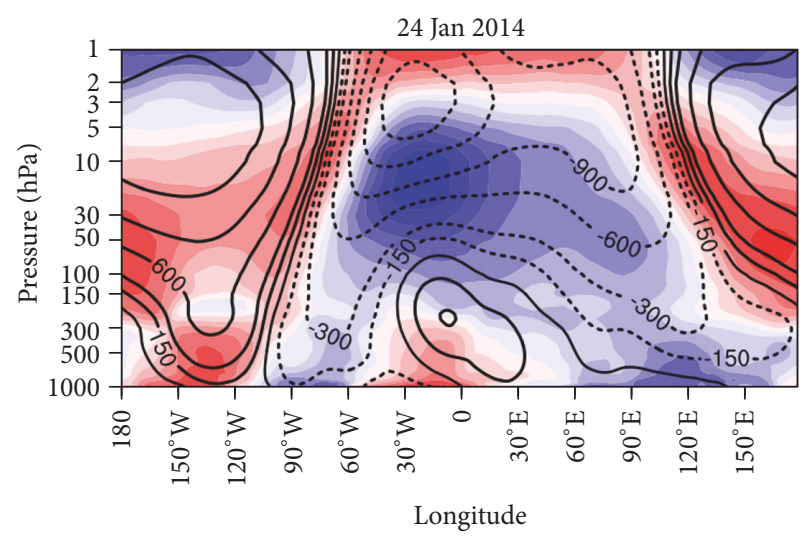

(b4)

Figure 5: Continued. 


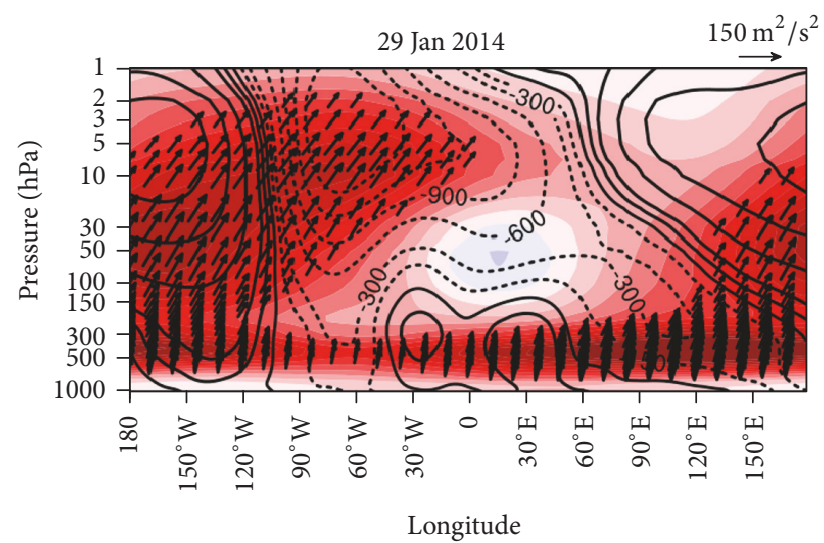

(a5) Waves 1-2

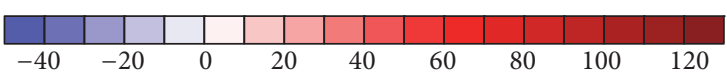

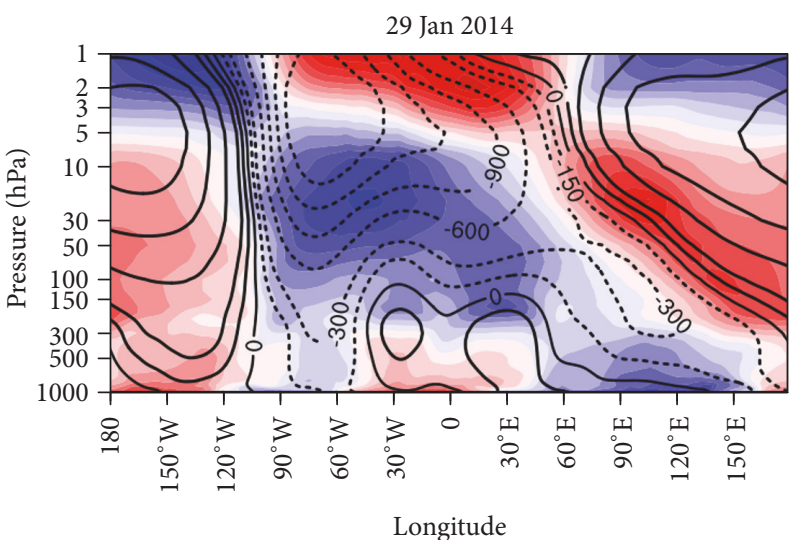

(b5)

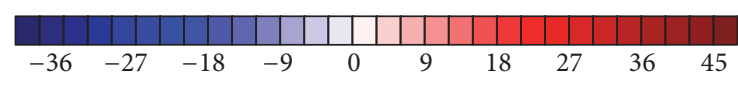

FIGURE 5: Longitude-pressure cross-sections of the daily $50^{\circ}-70^{\circ} \mathrm{N}$ mean zonal anomaly of geopotential height (contours; gpm), WAF (vectors: $>60 \mathrm{~m}^{2} \mathrm{~s}^{-2}$ only), and WAFz (shading; $\mathrm{m}^{2} \mathrm{~s}^{-2}$ ) of PWs 1 and 2 in January 2014 ((a1)-(a5)). ((b1)-(b5)) As in ((al)-(a5)), respectively, but for the geopotential height anomaly (contours; $\mathrm{m}$ ) and temperature (shading; K). WAF components are scaled by $\sqrt{1000 \mathrm{hPa} / \mathrm{p}}$ horizontally and by $100 \times \sqrt{1000 \mathrm{hPa} / p}$ vertically.

to end, and the surface high begins to weaken (Figure 6(b5)). It appears that Figure 6(a1) is significantly different from Figure 6(b1) in Atlantic area, suggesting that wave 4 may more favor the strengthening of upward wave flux over the Atlantic area. Also note that the effect of wave 4 on the tropospheric blocking over the west coast of North America cannot be negligible when comparing Figures 6(a3) and 6(b3).

The horizontal WAF of PWs 1 and 2 generally shows a poleward propagation in the high latitudes near the tropopause (Figures $7(\mathrm{al})-7(\mathrm{a} 5)$ ), which is the main channel for PWs entering the stratosphere (Figures 5(al)-5(a5)). However, the pattern of horizontal WAF involving waves 3 and 4 is significantly different (Figures $7(\mathrm{~b} 1)-7(\mathrm{~b} 5)$ ). During 19-29 January (Figures 7(b3)-7(b5)), the WAF of PWs 1-4 is along the Pacific-North America teleconnection (PNA) wave path, which contributes to the maintenance of the large amplitude disturbance of Rossby waves in North America. By comparing Figures 7(al)-7(a5) and Figures 7(b1)-7(b5), it is found that wave paths in the Pacific-North America region are mainly modulated by waves 3 and 4 . The stable strong disturbance of Rossby waves caused by the PNA wave path is helpful for the continuous invasion of cold air. Although the subplanetary-scale waves, such as PWs wave 3 and wave 4 , cannot propagate directly into the stratosphere, they can significantly affect the wave activity into the stratosphere and change the stratospheric circulation (Figure 6) by modulating PWs 1-2 through wave-wave interactions.

\section{Conclusions}

By diagnosing the evolution of wave activity, the present study finds that the subplanetary-scale waves have an important influence on the occurrence of the cold wave in east
North America in late January 2014. The positive anomaly of the stratospheric Atlantic high is the early background for the North American cold wave, and then the wave activity anomalies of subplanetary-scale waves represented by waves 3 and 4 contribute to the large-scale migration of wave energy through troposphere-stratosphere interactions, which is followed by the establishment of a local tropospheric circulation structure that is favorable to a cold wave.

The planetary-scale waves PWs 1 and 2 provide subplanetary-scale waves 3 and 4 with a stable circulation background. The continuous upward WAFs of PWs 1 and 2 in the East Asia-Pacific region maintain the Pacific high in the stratosphere. The propagation anomalies of Rossby waves between the troposphere and the stratosphere are due to the modulating effects of waves 3 and 4 on PWs 1 and 2 . At the extended range scale, the modulating effects help strengthen the upward and eastward WAFs over the Atlantic region, enhancing the Pacific high in the stratosphere in its early stage. About ten days later, the downward WAFs over the east Pacific due to the modulating effects are beneficial to downward development of the stratospheric high over the Pacific and formation of the tropospheric blocking high over west coast of North America accompanied by a strong adjacent cold low on the east side.

This cold wave is an important aspect of troposphere-stratosphere interaction. The energy redistribution through the troposphere-stratosphere-troposphere is conducive to the maintenance of the PNA wave path, which contributes to the WAF over North America that causes the southward invasion of polar cold air into lower latitudes in east North America. Therefore, the wave activity anomaly of 


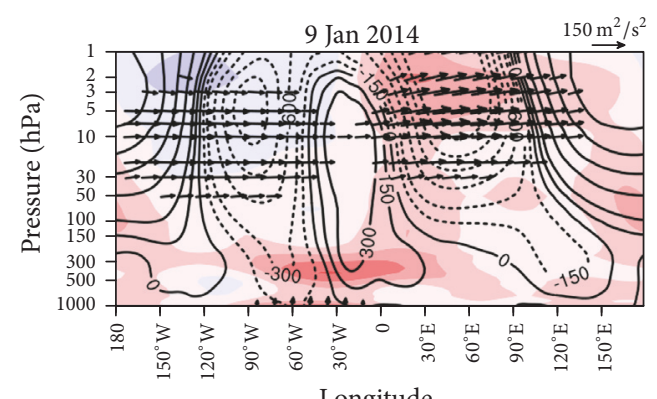

(a1) Waves 1-3

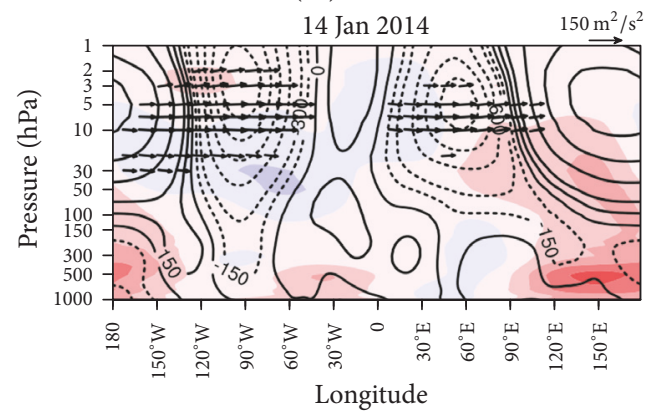

(a2) Waves 1-3

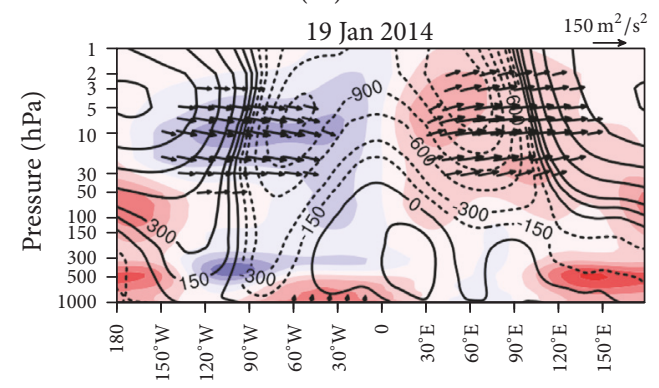

Longitude

(a3) Waves 1-3

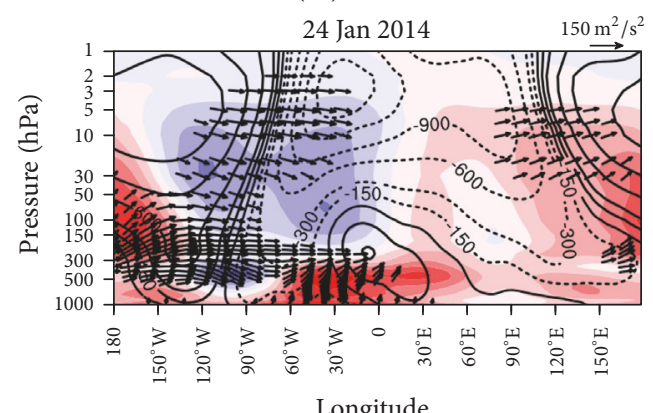

(a4) Waves 1-3

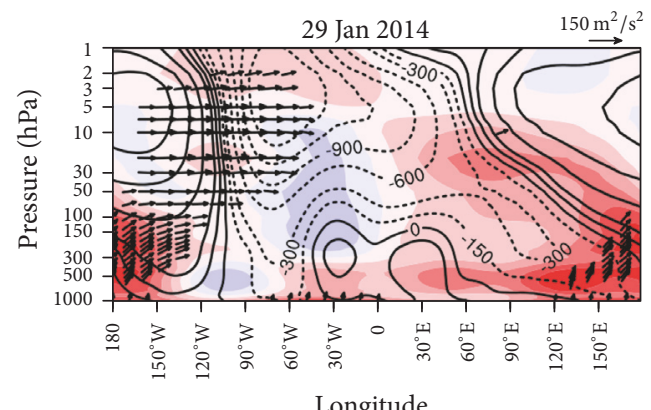

(a5) Waves

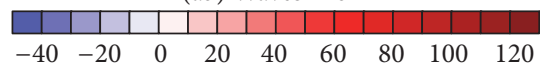

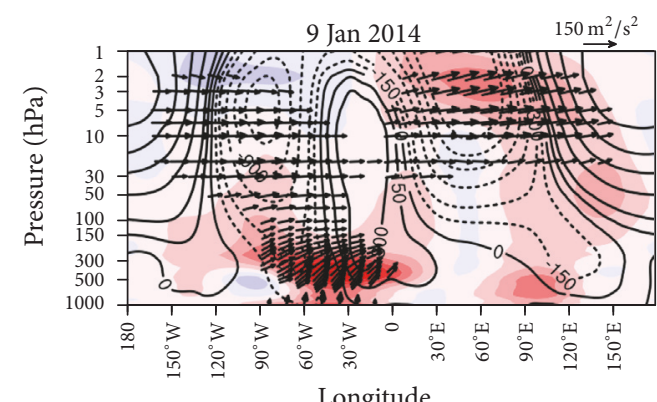

(b1) Waves 1-4

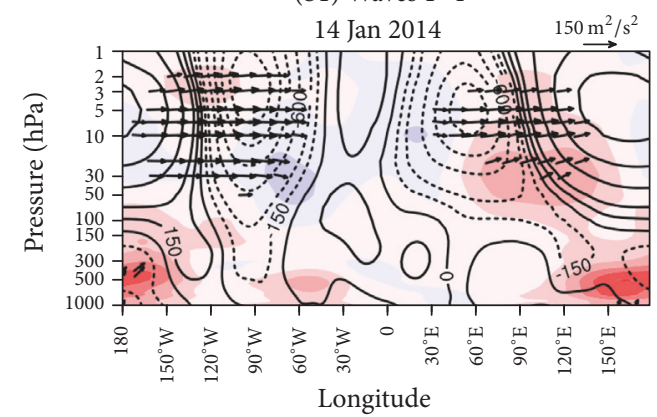

(b2) Waves 1-4

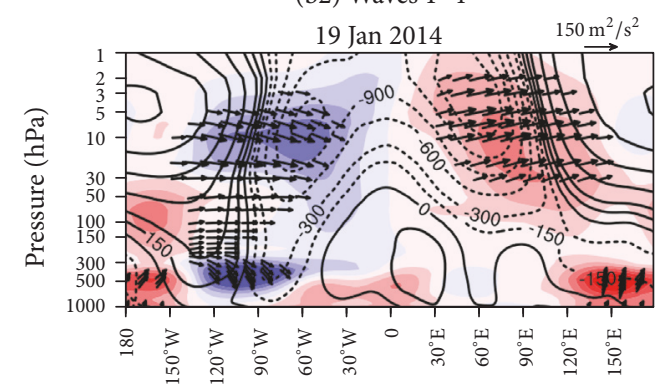

Longitude

(b3) Waves 1-4

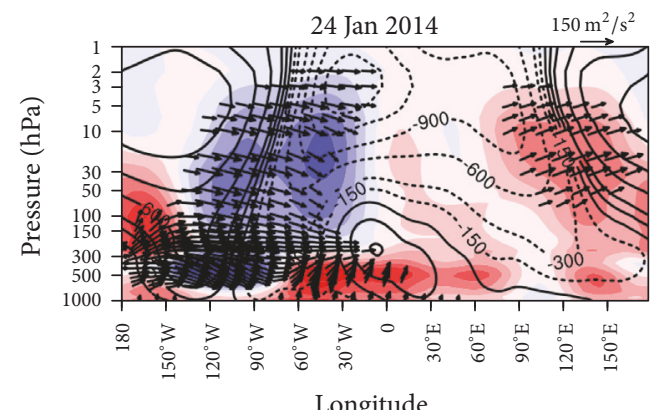

(b4) Waves 1-4

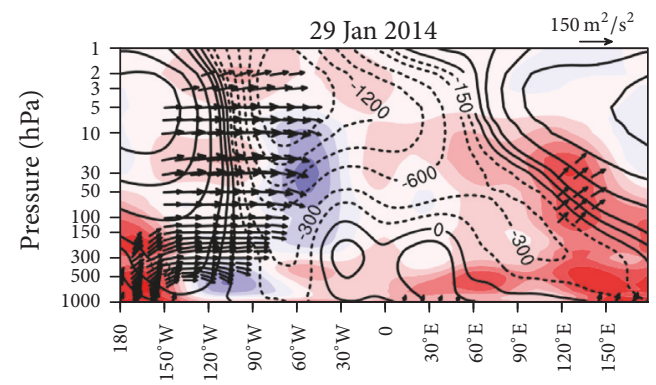

Longitude

(b5) Waves 1-4

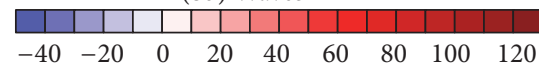

FIgURE 6: As in Figure 5 ((a1)-(a5)), but for waves 1-3 ((a1)-(a5)) and waves 1-4 ((b1)-(b5)). 


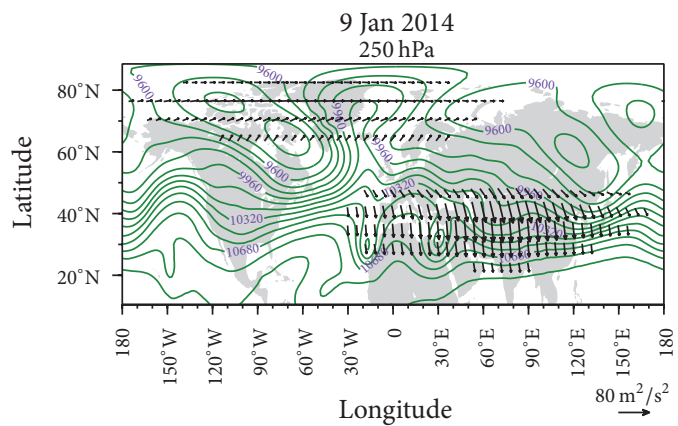

(a1) Waves 1-2

14 Jan 2014

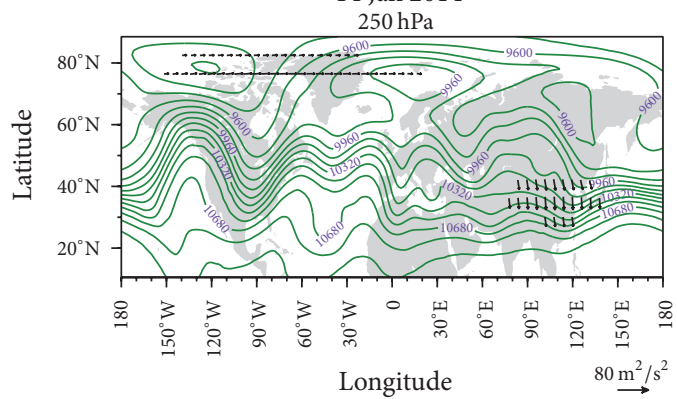

(a2) Waves 1-2

19 Jan 2014

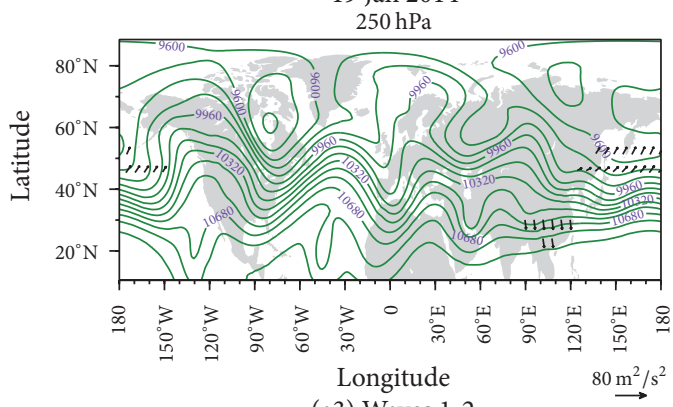

(a3) Waves 1-2

24 Jan 2014

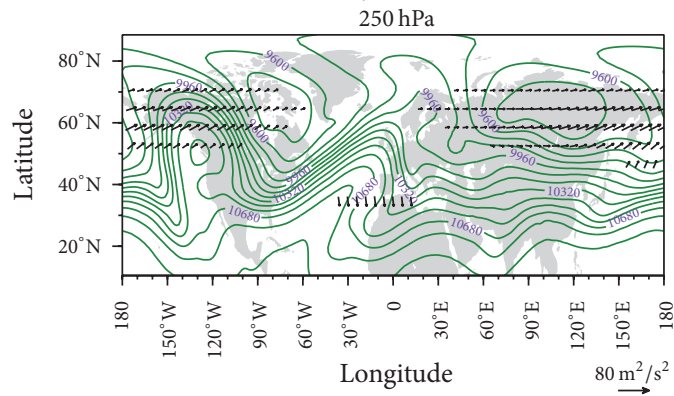

(a4) Waves 1-2

29 Jan 2014

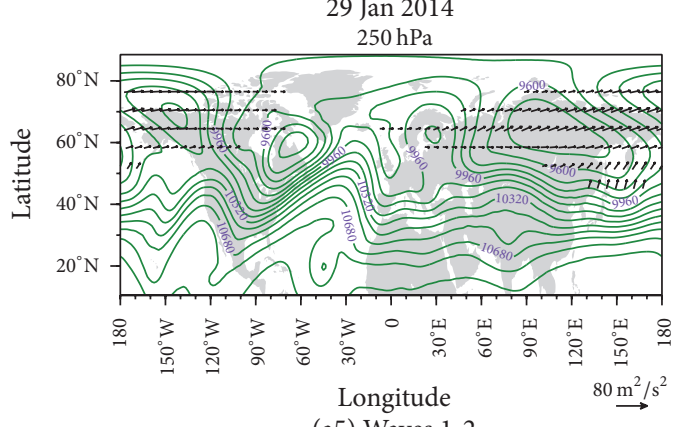

(a5) Waves 1-2

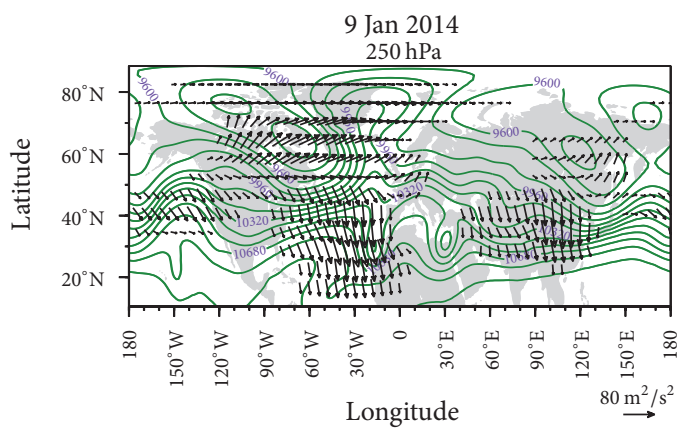

(b1) Waves 1-4

14 Jan 2014

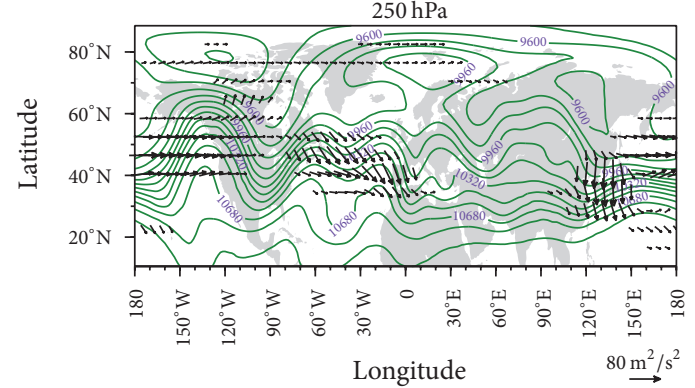

(b2) Waves 1-4

19 Jan 2014

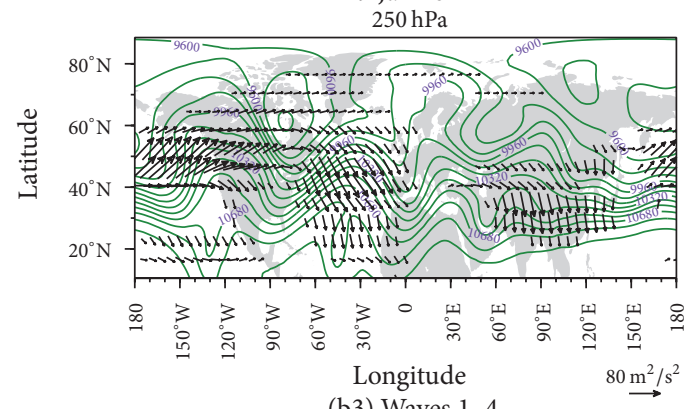

(b3) Waves 1-4

24 Jan 2014

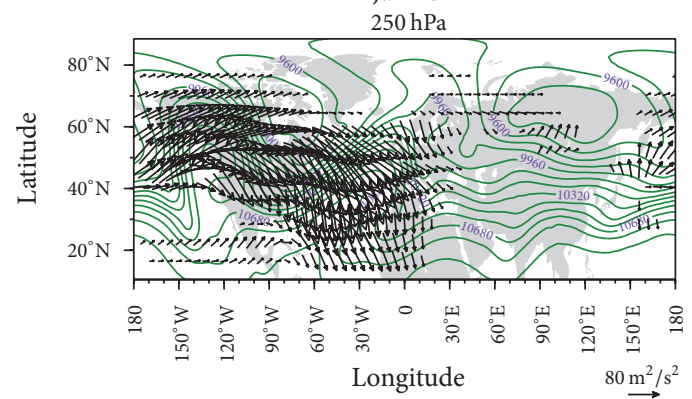

(b4) Waves 1-4

29 Jan 2014

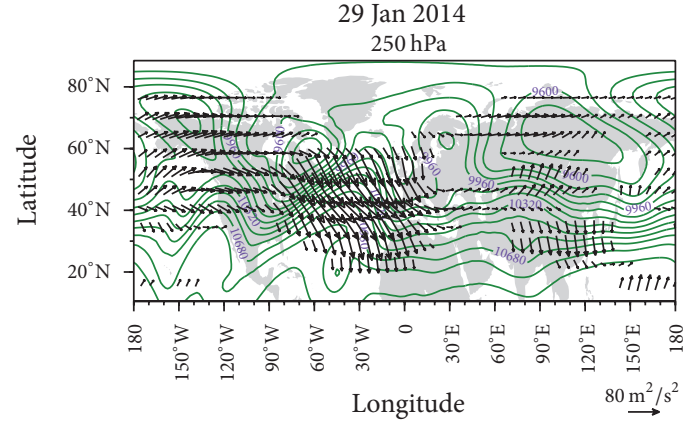

(b5) Waves 1-4

Figure 7: Daily geopotential height (contours; m) and WAFs (vectors: $>12 \mathrm{~m}^{2} \mathrm{~s}^{-2}$ only) of PWs 1 and 2 ((a1)-(a5)) and waves 1-4 ((b1)-(b5)) at $250 \mathrm{hPa}$ in January 2014. Contour interval: $120 \mathrm{gpm}$. 
subplanetary-scale waves represented by waves 3 and 4 is the most important factor contributing to this cold wave.

\section{Conflicts of Interest}

The authors declare no conflicts of interest.

\section{Acknowledgments}

The provisions of online data by ECMWF are gratefully acknowledged. This study was supported by National Natural Science Foundation of China (Grant nos. 41375047, 91537213, and 41675039) and the Priority Academic Program Development of Jiangsu Higher Education Institutions (PAPD).

\section{References}

[1] K. Kodera and Y. Kuroda, "Tropospheric and stratospheric aspects of the Arctic Oscillation," Geophysical Research Letters, vol. 27, no. 20, pp. 3349-3352, 2000.

[2] D. M. Mitchell, L. J. Gray, J. Anstey, M. P. Baldwin, and A. J. Charlton-Perez, "The influence of stratospheric vortex displacements and splits on surface climate," Journal of Climate, vol. 26, no. 8, pp. 2668-2682, 2013.

[3] J. Zhang, W. Tian, M. P. Chipperfield, F. Xie, and J. Huang, "Persistent shift of the Arctic polar vortex towards the Eurasian continent in recent decades," Nature Climate Change, vol. 6, no. 12, pp. 1094-1099, 2016.

[4] G. Xiong, Q. Chen, K. Zhu, and G. Fan, "Relationship between stratospheric polar vortex change and temperature, precipitation in winter of China," Plateau Meteorology, vol. 31, no. 4, pp. 1001-1006, 2012.

[5] S. Deng, Y. Chen, T. Luo, Y. Bi, and H. Zhou, "The possible influence of stratospheric sudden warming on East Asian weather," Advances in Atmospheric Sciences, vol. 25, no. 5, pp. 841-846, 2008.

[6] Q. Chen, L. Xu, and H. Cai, "Impact of Stratospheric Sudden Warming on East Asian Winter Monsoons," Advances in Meteorology, vol. 2015, Article ID 640912, 2015.

[7] D. Wang, C. Liu, Y. Liu et al., "A preliminary analysis of features and causes of the snow storm event over the Southern China in January 2008," Acta Meteorologica Sinica, vol. 66, no. 3, pp. 405-422, 2008

[8] W. Chen and K. Wei, "Anomalous proapagation of the quasistationary planetary waves in the atmosphere and its roles in the impact of the stratosphere on the East Asia winter cliamate (in Chinese)," Advances in Earth Science, vol. 24, no. 3, pp. 272-285, 2009.

[9] L. Wei, Q. Chen, B. Chen, and X. Liu, "Variabilities of the stratospheric polar vortex and the influence on the weather of China in the boreal winter," Chinese Journal of Atmospheric Sciences, vol. 38, no. 3, pp. 551-562, 2014.

[10] J.-H. Jeong, B.-M. Kim, C.-H. Ho, D. Chen, and G.-H. Lim, "Stratospheric origin of cold surge occurrence in East Asia," Geophysical Research Letters, vol. 33, no. 14, Article ID L14710, 2006.

[11] A. Solomon, "Wave activity events and the variability of the stratospheric polar vortex," Journal of Climate, vol. 27, no. 20, pp. 7796-7806, 2014.
[12] M. P. Baldwin, D. W. J. Thompson, E. F. Shuckburgh, W. A. Norton, and N. P. Gillett, "Weather from the stratosphere?" Science, vol. 301, no. 5631, pp. 317-319, 2003.

[13] Y. Song and W. A. Robinson, "Dynamical mechanisms for stratospheric influences on the troposphere," Journal of the Atmospheric Sciences, vol. 61, no. 14, pp. 1711-1725, 2004.

[14] T. Chshyolkova, A. H. Manson, C. E. Meek et al., "Polar vortex evolution during Northern Hemispheric winter 2004/05," Annales Geophysicae, vol. 25, no. 6, pp. 1279-1298, 2007.

[15] B. Tan, "Advances of atmospheric of Rossby waves dynamics," Acta Meteorologica Sinica, vol. 66, no. 6, pp. 870-879, 2008.

[16] J. K. Angell and J. Korshover, "Variation in size and location of the 300 mb north circumpolar vortex between 1963 and 1975," Monthly Weather Review, vol. 105, no. 1, pp. 19-25, 1977.

[17] J. K. Angell, "Relation between 300-mb north polar vortex and equatorial sst, qbo, and sunspot number and the record contraction of the vortex in 1988-89," Journal of Climate, vol. 5, no. 1, pp. 22-29, 1992.

[18] S. Gu and X. Yang, "Variability of the northern circumpolar vortex and its association with climate anomaly in China," Acta Meteorologica Sinica, vol. 26, no. 2, pp. 135-142, 2006.

[19] Z. Jia, X. Wen, Y. Hu, and Y. Guo, "Amplication of stratospheric NAM signal to winter climate prediction," Journal of Applied Meteorological Science, vol. 25, no. 1, pp. 107-111, 2014.

[20] L. Sun, H. Wu, and X. Li, "Our Understanding of arctic vortex," Chinese Journal of polar research, vol. 18, no. 1, pp. 52-62, 2006.

[21] D. P. Dee, S. M. Uppala, and A. J. Simmons, “The ERA-Interim reanalysis: configuration and performance of the data assimilation system," Quarterly Journal of the Royal Meteorological Society, vol. 137, no. 656, pp. 553-597, 2011.

[22] H. J. Edmond Jr., B. J. Hoskins, and M. E. McIntyre, "EliassenPalm cross sections for the troposphere." Journal of the Atmospheric Sciences, vol. 37, no. 12, pp. 2600-2616, 1980.

[23] R. A. Plumb, "On the three-dimensional propagation of stationary waves," Journal of the Atmospheric Sciences, vol. 42, no. 3, pp. 217-229, 1985.

[24] C. Shi, T. Xu, D. Guo, and Z. Pan, "Modulating effects of planetary wave 3 on a stratospheric sudden warming event in 2005," Journal of the Atmospheric Sciences, vol. 74, no. 5, pp. 1549-1559, 2017. 

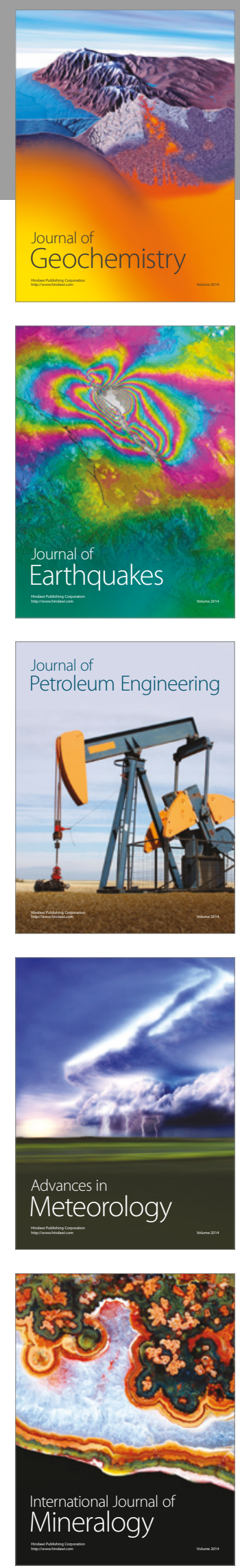
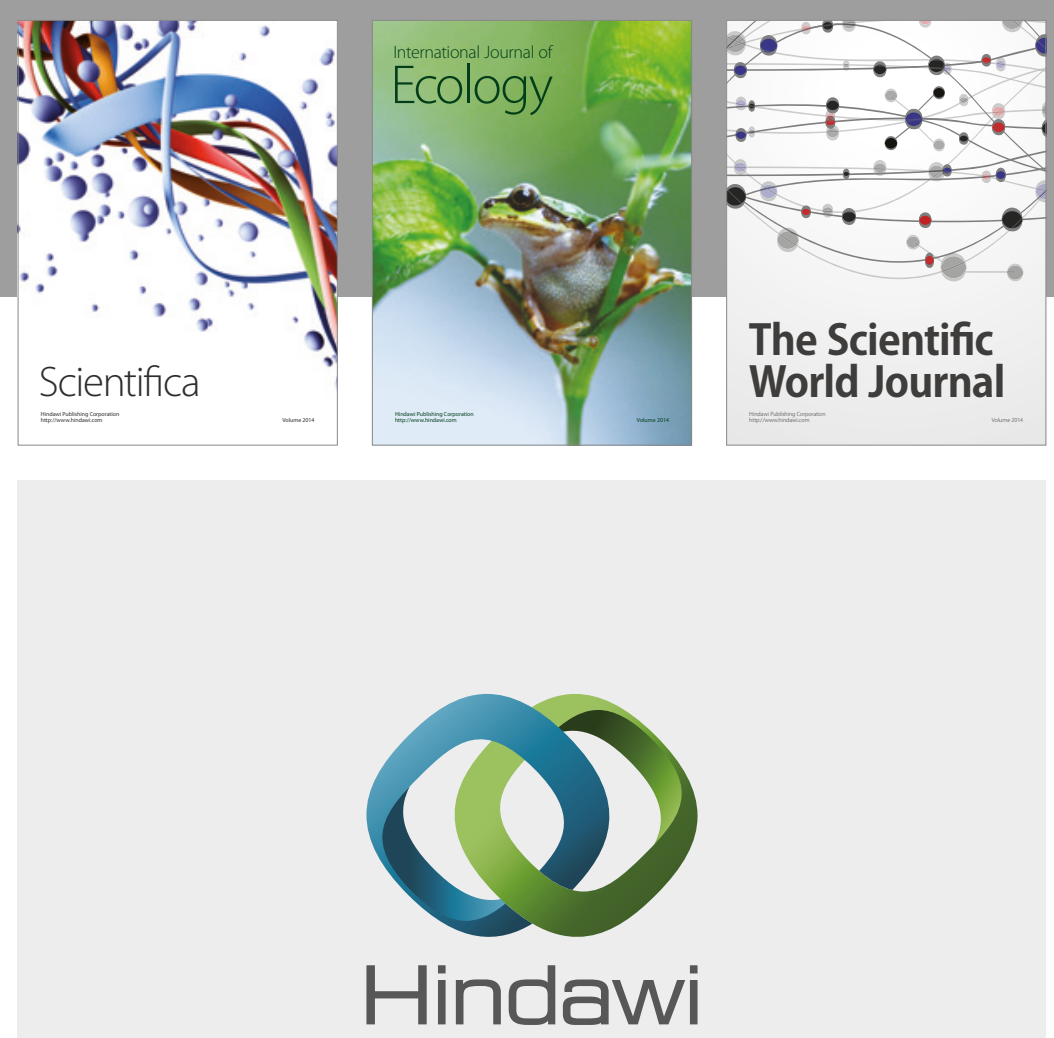

Submit your manuscripts at

https://www.hindawi.com
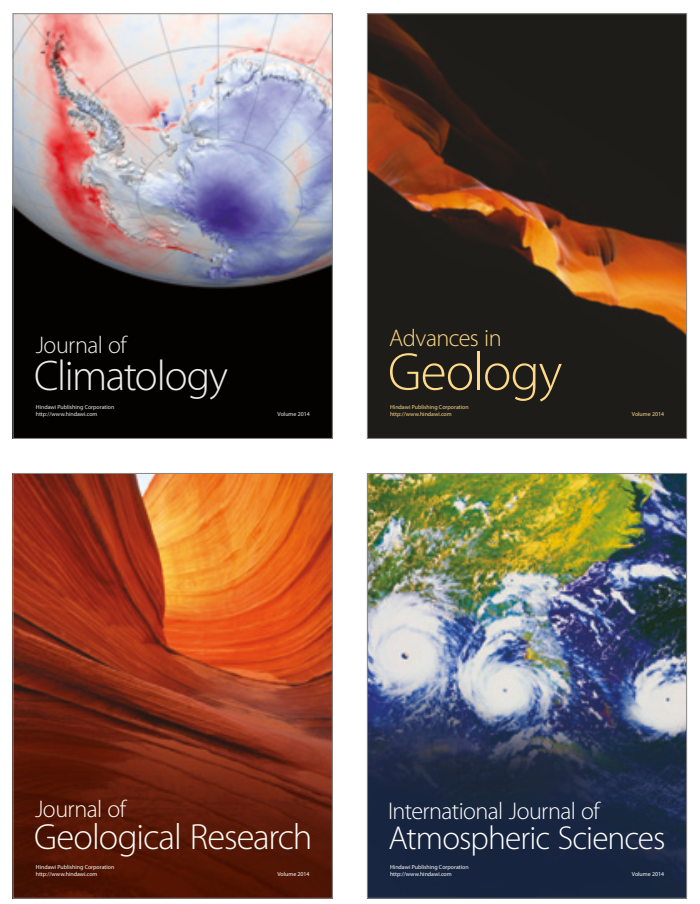

The Scientific

World Journal
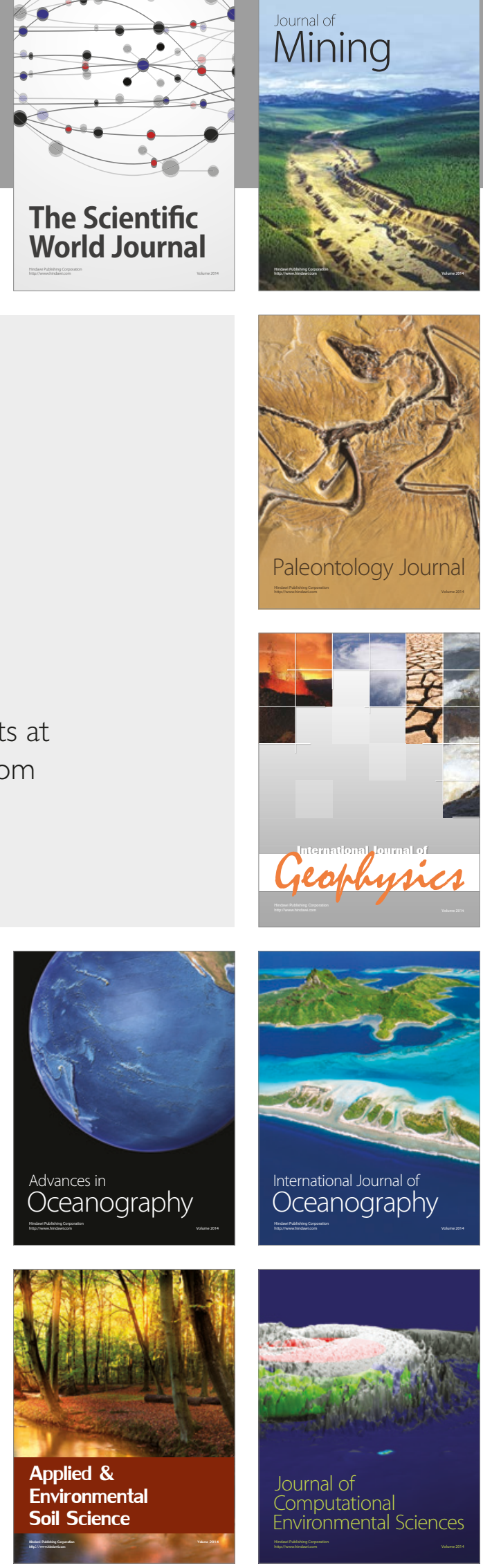